\title{
Improving Recovery Through Surfactant Desorption on An Oil Wet Limestone Reservoir
}

\section{Prince MJA*}

Department of Petroleum Engineering, AMET University, Chennai - 603112, Tamil Nadu, India

\begin{abstract}
The current paper investigates on reducing surfactant adsorption after its application onto limestone surface by Ethelene Oxide (EO) conjugated with Sodium Dodecyl Sulphonate (SDS) to improve oil recovery. SDS has been treated with $\mathrm{EO}$ as a nonionic surfactant with low critical micelle concentration to increase its hydrophilic nature that leads to desorb itself from oil wet surfaces like limestone reservoirs after altering wettability.

Although, surfactant has a great impact on Oil recovery, adsorption makes them ineffective. It's been a great concern for petroleum industry during enhanced oil recovery operations. This study focuses on finding a mechanism to reduce SDS adsorption on an oil wet limestone core sample and altering its wettability through EO at different concentrations.

Critical Micelle Concentration (CMC) of SDS was found at $500 \mathrm{ppm}$ by conductivity test was chosen to reduce interfacial tension between oil and brine composition. Due to surface charge variation SDS was observed to adsorb onto limestone surface through core analysis. It has been flooded after water under core flooding operations, which shows near to field observations. For reducing this effect, EO was introduced with different concentrations to alter the hydrophilic properties of SDS. Being limestone oil wet surface, which leads SDS to adsorb onto its surface.

Since, SDS would adhere onto the inner layers of core lead to alter wettability by recovering crude. The recovery of crude from a limestone core has been carried in two ways. Firstly, SDS was treated to get adsorb onto the core surface and secondly desorption of SDS by enhancing its hydrophilic nature through EO. By its application, the recovery of oil has been improved by reduction in adsorption of SDS successfully have been reported.
\end{abstract}

Keywords: Wettability alteration; Surfactant adsorption; Core flooding; Critical micelle concentration

\section{Introduction}

Globally, there is more than $50 \%$ of known oil reserves are in carbonate structures. The majority being oil wet primary and secondary recoveries are not sufficient to extract complete oil. Selection of a proper EOR method is required to alter the complex nature of carbonate reservoirs, lead more challenges in chemical flooding operations. Almost an average of $60 \%$ OOIP is left behind primary or secondary operations, majority at deep Oil wells. The concern area for surfactant application onto carbonate reservoirs has been limited to laboratories [1]. The unique structure and ability to alter surface properties makes surfactant more reliable for enhancing recovery [2].

Chemical flooding operations are less satisfied due to adsorption of surfactants on reservoir rocks and precipitation [3]. Adsorption and wettability depends on oil composition, structure of surfactants, blending mechanism and surface properties of rock. The mineral composition of rock plays a major role in adsorption and wettability alterations, which acts at solid liquid interface [4].

The application of surfactants on fields is limited because of fluctuations in oil prices. Even though some laboratory results are promising, the major concern is the large-scale availability of surfactants [5].

Adsorption of surfactant is the adherence of nonpolar molecules of surfactants which are organic in nature onto the carbonate surface by ion exchange and lipophillic bonding [6]. The adsorption depends on the availability of divalent ions, salinity and HLB ratio. Adsorption of surfactants means the loss in altering the surface properties which is uneconomical for chemical enhanced oil recovery [7].
Surfactant adsorption onto the surface depends on double layer at interface where there is polarity in charges [8]. At low concentrations, the adsorption is dependent on electric double layer. But at high concentrations near to CMC it depends on salinity, HLB and ionic strength. The adsorption of anionic surfactants has been observed to increase by increasing salt concentration (salinity), temperature and $\mathrm{pH}$ by addition of alkali [9].

In the current study, adsorption of surfactants has been reported at different temperatures with salt concentrations. SDS has been chosen to alter wettability for carbonate samples at CMC level. Due to high adsorption, the recovery of oil was observed to be low. The application of $\mathrm{EO}$ at different concentrations to reduce adsorption and enhancing oil recovery additional to the recovery obtained through SDS has been reported.

\section{Experimental Methodology}

\section{Core flooding apparatus}

The apparatus consists of a $3^{11} \times 5^{11}$ core holder which holds cores

"Corresponding author: Prince MJA, Department of Petroleum Engineering AMET University, Chennai - 603112, Tamil Nadu, India, Tel: +91 - 4426161180 ; E-mail: prince466@gmail.com

Received January 28, 2016; Accepted February 25, 2017; Published February 28, 2017

Citation: Prince MJA (2017) Improving Recovery Through Surfactant Desorption on An Oil Wet Limestone Reservoir. J Pet Environ Biotechnol 7: 319. doi 10.4172/2157-7463.1000319

Copyright: () 2017 Prince MJA. This is an open-access article distributed under the terms of the Creative Commons Attribution License, which permits unrestricted use, distribution, and reproduction in any medium, provided the original author and source are credited. 


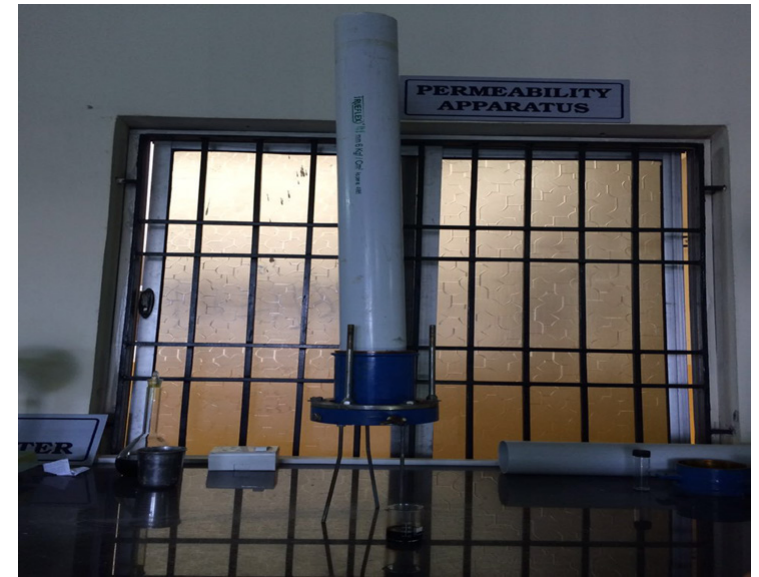

Figure 1: Capillary pressure curves.

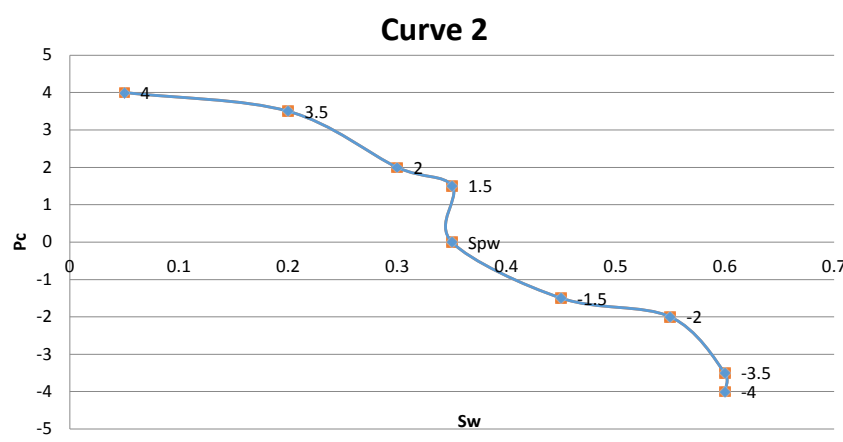

Figure 2: Imbibition of water.

of diameter less than its inner diameter of 3 inch as shown in Figure 1. Cores of $3^{11} \times 3^{11}$ has been kept inside core holder and mounted by an inlet tube. To make the core static it has been cemented between the inner surface of core holder and inlet tube. At the end of core holder, a porous plate has been mounted to bypass fluids from the core.

Cores can be flooded with low pressures based on column height to extract fluids from core. Wettability of a core sample can be calculated by constructing capillary pressure curves through core flooding. Capillary pressures are measured as the pressure difference between nonwetting oil phase and wetting water phase.

\section{Curve 1: First drainage of water}

Clean and dry limestone Cores have been placed inside core holder. Initially core has been flooded by water injected through inlet column. The pore volume of cores will be saturated by water has been displaced by oil injection. The pressure exerted by water inside core is wetting phase pressure $(\mathrm{Pw})$ and the pressure by oil is non-wetting phase pressure (Po). Po has to reach higher than $\mathrm{Pw}$ will result in displacing water by oil. The resultant $\mathrm{Pc}$ will be positive and reaches maximum until the oil breakthrough at outlet. This indicates complete drainage of water by oil and the core is left with connate water saturation (Sw).

\section{Curve 2: First imbibition of oil}

The core of complete oil saturation with Sw would be displaced by water injection. Water has to be injected slowly to displace oil until the curve reaches Zero. At Pc zero the water saturation will be recorded as Spontaneous water saturation (Spw) which indicated water have been saturated by itself or spontaneously. From here a little more pressure has to be applied on water to displace remaining oil in place until it reached residual state recorded as (Sor). The Pc would move towards extreme negative.

\section{Curve 3: Second drainage of water}

The process of oil injection will be repeated like curve 1. Slow injection of oil is preferable to displace water and to reach Pc at zero. At this level oil have been saturated in core spontaneously by itself and recorded as Spontaneous oil saturation(Spo) [10].

\section{Estimation of wettability}

Wettability is the nature of a reservoir to have partial attraction towards a fluid. Limestone samples have been aged with oil at reservoir conditions in a core oven. Then it has been cleaned by soxhlet apparatus with the treatment of heptane. Through core analysis with water and oil simultaneous flooding saturation exponents can be observed by constructing capillary pressure curves. The core has been found to be oil wet by amott wettability index. According to Amott wettability Index

$$
\begin{aligned}
& \mathrm{I}_{\mathrm{w}} \text { is imbibation of water and } \mathrm{I}_{\mathrm{o}} \text { is imbibation of oil } \\
& I_{w}=\frac{S_{s p w}-S_{c w}}{1-S_{c w}-S_{o r}} \text { and } I_{o}=\frac{S_{s p o}-S_{o r}}{1-S_{c w}-S_{o r}}
\end{aligned}
$$

If the difference between imbibation of water and oil is negative then core is Oil wet and positive for water wet. The core is intermediate wet at zero [11].

\section{Critical micelle concentration test}

Micelle is a form of droplet appears at the interface of oil and water by addition of surfactants. The formation of droplet will increase by increasing surfactant concentration [12]. At specific concentration, the micelle will appear with its lowest size leads to lower IFT at optimum. The concentration, where IFT is minimum is considered to be critical micelle concentration of that surfactant can be analyzed by conductivity [13]

In this test conductivity rises with increasing concentration of surfactants until the formation of micelle is completed [14]. Beyond addition of surfactants will increase the number of micelles, which has no effect on conductivity [15]. CMC can be observed by a peak variation on a graph between conductivity and surfactant concentration shown in Figure 2.

\section{Emulsion tests}

In this test, the concentration which has been chosen for core flooding operation should be suited for dissolution [16]. The CMC concentration from conductivity test will be tested with different proportions of brine and alkali for complete de emulsification. The suited proportion will be chosen by observing three clear layers in an emulsion after treatment with surfactants [17].

In the second stage, the selected proportion from first stage of three layers has been treated with $\mathrm{EO}$ at different concentration to increase hydrophilic nature by increasing HLB.

\section{HLB calculation}

EO mol. wt $=44 \mathrm{~g} / \mathrm{mol}$ hydrophilic nonionic surfactant,

SDS mol. $\mathrm{wt}=288.44 \mathrm{~g} / \mathrm{mol}$, 
Citation: Prince MJA (2017) Improving Recovery Through Surfactant Desorption on An Oil Wet Limestone Reservoir. J Pet Environ Biotechnol 7: 319. doi: $10.4172 / 2157-7463.1000319$

Page 3 of 5

\begin{tabular}{|c|c|c|c|c|c|c|c|c|}
\hline \multicolumn{3}{|c|}{ Curve 1} & \multicolumn{3}{|c|}{ Curve 2} & \multicolumn{3}{|c|}{ Curve 3} \\
\hline $\begin{array}{l}\text { Capillary Pressures } \\
(\mathrm{Po}-\mathrm{Pw}) \mathrm{psi}\end{array}$ & $\mathrm{S}_{0}$ & $\mathrm{~S}_{\mathrm{w}}$ & $\begin{array}{l}\text { Capillary Pressures } \\
\text { (Po-Pw) psi }\end{array}$ & $\mathrm{S}_{0}$ & $\mathrm{~S}_{\mathrm{w}}$ & $\begin{array}{l}\text { Capillary Pressures } \\
(\mathrm{Po}-\mathrm{Pw}) \mathrm{psi}\end{array}$ & $\mathrm{s}_{\mathrm{o}}$ & $\mathrm{S}_{\mathrm{w}}$ \\
\hline 1 & 0 & 1 & 3.5 & 0.8 & 0.2 & -4 & 0.4 & 0.6 \\
\hline 1.5 & 0.2 & 0.8 & 2 & 0.7 & 0.3 & -3.5 & 0.45 & 0.55 \\
\hline 2 & 0.6 & 0.4 & 1.5 & 0.65 & 0.35 & -2 & 0.5 & 0.5 \\
\hline 3 & 0.95 & 0.05 & 0 & 0.65 & $0.35 \mathrm{Spw}$ & -1.5 & 0.65 & 0.35 \\
\hline 4 & 0.95 & $0.05 \mathrm{Scw}$ & -1.5 & 0.55 & 0.45 & 0 & 0.75 Spo & 0.25 \\
\hline 4 & 0.95 & 0.05 & -2 & 0.45 & 0.55 & 0 & 0.75 & 0.25 \\
\hline 4 & 0.95 & 0.05 & -3.5 & 0.4 & 0.6 & 0 & 0.75 & 0.25 \\
\hline 4 & 0.95 & 0.05 & -4 & 0.4 Sor & 0.6 & 0 & 0.75 & 0.25 \\
\hline
\end{tabular}

Table 1: Capillary pressures vs. saturations.

\begin{tabular}{|c|c|c|c|}
\hline $\begin{array}{c}\text { Number of } \\
\text { emulsions }\end{array}$ & $\begin{array}{c}\text { Brine } \\
\text { Concentration in } \\
\text { moles }\end{array}$ & $\begin{array}{c}\text { SDS } \\
\text { Concentration in } \\
\text { ppm }\end{array}$ & $\begin{array}{c}\text { Conductivity mS/ } \\
\text { cm }\end{array}$ \\
\hline 1 & 0.5 & 200 & 10.5 \\
\hline 2 & 0.5 & 300 & 17.5 \\
\hline 3 & 0.5 & 400 & 26.2 \\
\hline 4 & 0.5 & 500 & 30.1 \\
\hline 5 & 0.5 & 600 & 30.2 \\
\hline 6 & 0.5 & 700 & 30.2 \\
\hline
\end{tabular}

Table 2: SDS concentrations for conductivity.

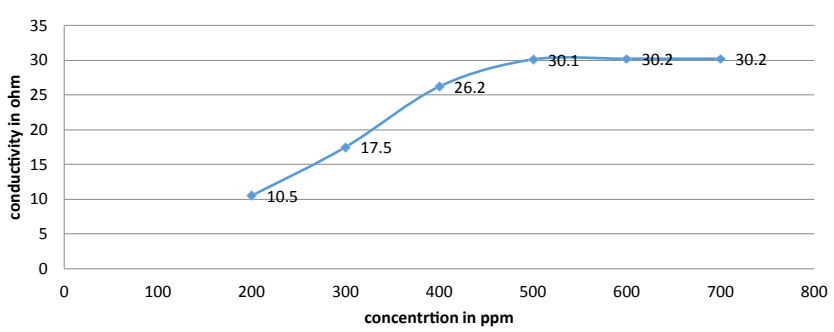

Figure 3: CMC by conductivity.

Hlb calculation for mixture of 10mole SDS and 20 mole EO will be

$\mathrm{HLB}=\left(20^{\star} 44\right) /\left(\left(20^{\star} 44\right)+\left(10^{\star} 288.44\right)\right)=0.23$

$0.23^{\star} 100=23$

$$
\mathrm{HLB}=23 / 5=4.6
$$

Six different emulsions with EO has been prepared and treated separately in core flooding operation. The increase in HLB will raise water solubility by addition of $\mathrm{EO}$ and reduces adsorption on an oil wet surface reservoirs.

\section{Results}

The limestone core has been saturated in oil for seven days to make it oil wet before core flooding. Then during core flooding capillary pressure curves were constructed to observe the level of wettability shown in Table 1.

According to amott wettability Index formulae Iw $=0.55$ and Io $=0.64$

Iw-Io $=-0.09$, which indicated oil wet.

After wettability, CMC was estimated by preparing six concentrations of Sodium dodecyle sulphonate (SDS) surfactants from $200 \mathrm{ppm}$ to $700 \mathrm{ppm}$ as shown in Table 2. The CMC has been observed at $500 \mathrm{ppm}$ due to sharp deviation observed on graph between conductivity vs. concentration shown in Figure 3. After selecting 500 ppm of SDS as suitable concentration, six emulsions were prepared with different proportions shown in Table 3.

From the emulsion test 500 ppm of SDS with $1 \%$ wt alkali was observed to appear three clear layers as shown in Figure 4.

The pore volume ( PV) of core sample has been calculated to be $30.5 \mathrm{cc}$ by Ruska porometer. During core analysis, core has been injected by $2 \mathrm{PV}$ of water for 2 days with Pc of $0.09 \mathrm{psi}$, where 1.35 PV was collected at outlet. Then 2 PV of oil has been injected into core to displace water. Upto $0.6 \mathrm{PV}$ out of $0.65 \mathrm{PV}$ saturated water was collected at outlet. The remaining water was considered as connate water saturation Scw of $0.05 \mathrm{PV}$ at Pc of 4 psi shown in Figure 5. At outlet, $0.85 \mathrm{PV}$ out of $2 \mathrm{PVoil} \mathrm{has} \mathrm{been} \mathrm{collected.} \mathrm{It} \mathrm{shows} \mathrm{core} \mathrm{have}$ been saturated and adsorbed with $1.15 \mathrm{PV}$ of oil and $0.05 \mathrm{PV}$ of connate water. Since, the core has a space limit of $1 \mathrm{PV}$ with consideration of $0.05 \mathrm{PV}$ of Scw the total absorbed amount of oil was observed to be 0.2 $\mathrm{PV}$ apart from saturated $1 \mathrm{PV}$.

\begin{tabular}{|c|c|c|c|c|c|}
\hline $\begin{array}{c}\text { Number of } \\
\text { emulsions }\end{array}$ & $\begin{array}{c}\text { SDS ppm in } \\
\mathbf{1 5 m l}\end{array}$ & $\mathbf{N a C l} \mathbf{w t} \%$ & $\begin{array}{c}\mathbf{N a}_{2} \mathbf{C O}_{3} \\
\mathbf{w t} \%\end{array}$ & $\begin{array}{c}\text { Appearance } \\
\text { in layers }\end{array}$ & Inference \\
\hline 1 & 500 & 0.0 & 0.0 & 1 phase & w/o emulsion \\
\hline 2 & 500 & 0.5 & 0.0 & 2 phases & $\begin{array}{c}\text { slightly w/o } \\
\text { emulsion }\end{array}$ \\
\hline 3 & 500 & 1.0 & 0.0 & 2 phases & $\begin{array}{c}\text { Light w/o } \\
\text { emulsion }\end{array}$ \\
\hline 4 & 500 & 0.0 & 0.5 & 2 phases & $\begin{array}{c}\text { Light w/o } \\
\text { emulsion }\end{array}$ \\
\hline 5 & 500 & 0.0 & 1.0 & $\begin{array}{c}3 \text { clear } \\
\text { phases }\end{array}$ & $\begin{array}{c}\text { De } \\
\text { emulsification }\end{array}$ \\
\hline 6 & 500 & 0.5 & 0.5 & 2 phases & $\begin{array}{c}\text { Light o/w } \\
\text { emulsion }\end{array}$ \\
\hline
\end{tabular}

Table 3: SDS concentrations with Nacl and alkali.

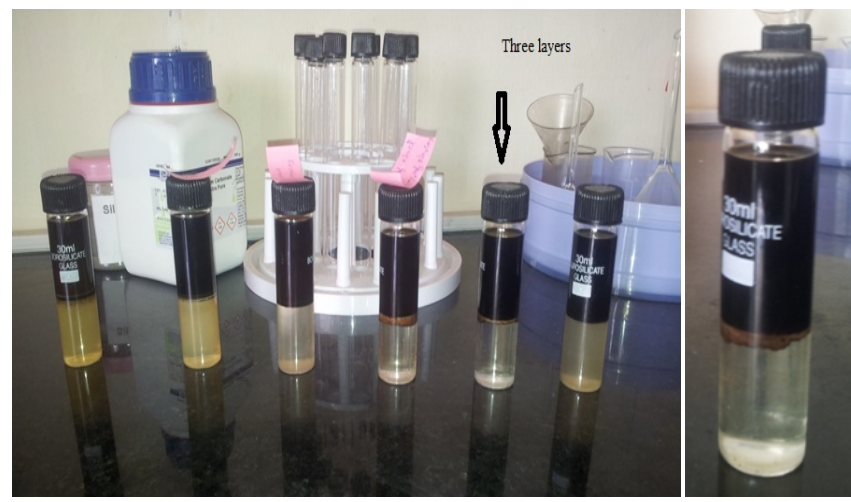

Figure 4: Six emulsion were prepared indicating three-layer middle micro emulsion. 


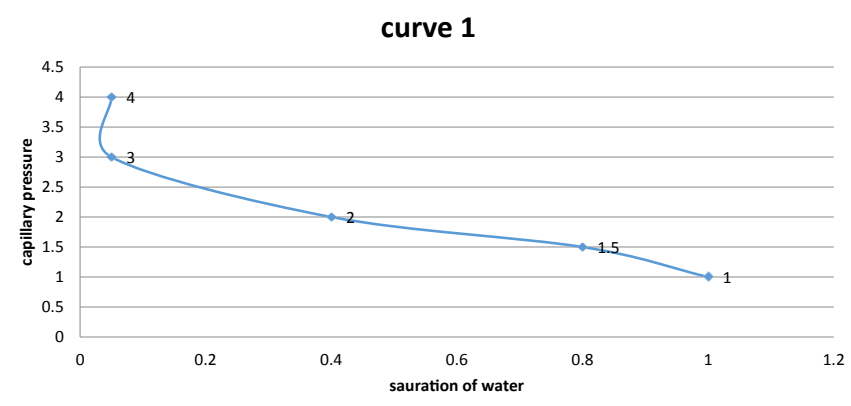

Figure 5: Drainage of water.

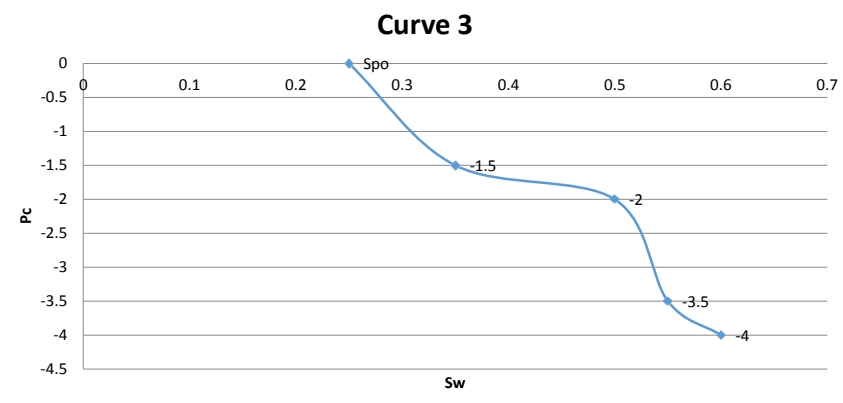

Figure 6: Second drainage of water

\begin{tabular}{|c|c|c|c|c|c|c|}
\hline \multicolumn{10}{|c|}{ ppm } & $\begin{array}{c}\text { Brine } \\
\text { wt \%. }\end{array}$ & $\begin{array}{c}\text { concentration } \\
\text { in moles }\end{array}$ & $\begin{array}{c}\text { SDS } \\
\text { ppm }\end{array}$ & HLB & $\begin{array}{c}\text { Oil recovery } \\
\text { in PV }\end{array}$ & $\begin{array}{c}\text { Surfactant } \\
\text { recovery SDS PV }\end{array}$ \\
\hline 1000 & 0.5 & 10 & 500 & 2.6 & 0.05 & 0.33 \\
\hline 2000 & 0.5 & 20 & 500 & 4.6 & 0.12 & 0.35 \\
\hline 3000 & 0.5 & 30 & 500 & 6.2 & 0.13 & 0.44 \\
\hline 4000 & 0.5 & 40 & 500 & 7.5 & 0.12 & 0.36 \\
\hline 5000 & 0.5 & 50 & 500 & 8.6 & 0.11 & 0.36 \\
\hline
\end{tabular}

Table 4: SDS concentration vs HLB.

The core sample was treated by injecting $5 \mathrm{PV}$ of water to displace oil at Pc of 4 psi. It leads to collect $0.55 \mathrm{PV}$ of oil out of $1.2 \mathrm{PV}$ at outlet until breakthrough. Water has been imbibed by displacing oil spontaneously upto both pressures were equal. The saturation of water at this level is considered to be spontaneous saturation of water Spw of $0.35 \mathrm{PV}$ beyond where additional pressure has been applied by injecting more water. Spw and Sor have been recorded at $0.35 \mathrm{PV}$ and 0.4 PV respectively shown in Figure 3. In that $0.2 \mathrm{PV}$ of oil is considered to be adsorbed. The left-out oil after water flooding is $0.4 \mathrm{PV}$ as Sor in that $0.05 \mathrm{PV}$ is connate water saturation. Water has been imbibed by displacing oil spontaneously upto both pressures were equal. The saturation of water at this level is considered to be spontaneous saturation of water of $0.35 \mathrm{PV}$ beyond where additional pressure has been applied by injecting more water. The residual oil saturation of oil was observed at $0.4 \mathrm{PV}$, where the water saturation was maximum upto $0.6 \mathrm{PV}$ as shown in Figure 3. The same process has been repeated by injecting oil to displace water until the capillary pressure becomes zero. Spontaneous oil saturation was recorded at this level to be $0.55 \mathrm{PV}$ of oil as shown in Figure 6.

\section{Discussion}

Surfactant flooding through CMC and Emulsion tests were initiated after water flooding. $5 \mathrm{PV}$ of diluted Emulsions has sent and $0.35 \mathrm{PV}$ out of 0.55 PV oil was collected until breakthrough. The surfactants were collected by inlet of $4.4 \mathrm{PV}$ and lost $0.6 \mathrm{PV}$ was observed to be absorbed by core. Remaining connate water 0.05 PV and residual oil $0.2 \mathrm{PV}$ were left behind.

In this test the loss of surfactant emulsion is the resultant of adsorption due to electrostatic charge polarity between carbonate minerals and SDS. This has been reduced by treating the same emulsion with EO has a HLB enhancer. EO leads to increase hydrophilic nature of surfactants contrary to core nature makes it desorbed and enhances recovery.

Before treating with EO, five different concentrations have been chosen for miscibility with the emulsions already sent into core by Table 4. These five concentrations have yield different recoveries of oil and surfactants. From the Table 4 it has been observed that $3000 \mathrm{ppm}$ of EO at HLB 6.2 is the effective combination that could recover oil of $0.13 \mathrm{PV}$ out of $2.0 \mathrm{PV}$ of $65 \%$ and SDS of $0.44 \mathrm{PV}$ of $0.6 \mathrm{PV}$ upto $73 \%$.

\section{Conclusion}

The application of surfactants onto carbonate reservoirs has been effective under chemical EOR process. During core flooding analysis, the loss of surfactants was observed due to opposite ion interaction with the surface. Capillary pressure curves are considered to be one of the effective methods for estimating wettability of a core sample. While constructing capillary pressure curves second drainage of water has been stopped at spontaneous saturation of oil which can be extended up to the level of complete water saturation. The recovery of oil was found to be less after surfactant flooding due to adsorption. It has been improved by increasing HLB of SDS by EO.

Methods for reducing adsorption of surfactants have a great scope for enhancing recovery of crude addition to its flooding. HLB is one among the most parameters have been altered by the treatment of EO. There may be other parameters which can reduce adsorption of surfactants has to investigated. This process can be extended for reducing adsorption onto dolomite and sandstone reservoirs.

\section{References}

1. Orivri DU, Taiwo OA, Olafuyi OA (2014) Characterizing wettability Effect on Recovery from Surfactant Flooding in a lighty oil Porous Media. The Journal of Nig. Institution of Prod. Engineers 17: 143-152.

2. Atsenuwa JB, Taiwo OA, Mohammed IU, Dala A, Olafuyi OA (2014) Effect of viscosity of heavy oil (Class-A) on oil recovery in SP flooding using lauryl sulphate and gum Arabic. SPE 172401, Presented at SPE-NAICE, Annual Meeting, Lagos.

3. Avwioroko JE, Taiwo OA, Mohammed IU, Dala JA, Olafuyi OA (2014) A laboratory study of ASP flooding on mixed wettability for heavy oil recovery using gum arabic as a polymer. SPE 172401, Presented at SPE-NAICE Annual Meeting, Lagos.

4. Raffa P, Wever DAZ, Picchioni F, Broekhuis AA (2015) Polymeric surfactants: Synthesis, properties, and links to applications. Chem. Rev. 115: 8504-8563.

5. Olajire AA (2014) Review of ASP EOR (alkaline surfactant polymer enhanced oil recovery) technology in the petroleum industry: prospects and challenges. Energy 77: 963-982

6. Raffa P, Brandenburg P, Wever DAZ, Broekhuis AA, Picchioni F (2013) Polystyrene-poly (sodium methacrylate) amphiphilic block copolymers by ATRP: effect of structure, $\mathrm{pH}$, and ionic strength on rheology of aqueous solutions. Macromolecules 46: 7106-7111.

7. Onuoha SO, Olafuyi OA (2013) Alkali/Surfactant/Polymer flooding using Gum Arabic; A comparative analysis. This paper was presented at the Nigeria Annual International Conference and Exhibition held in Lagos, Nigeria.

8. Xu F, Guo X, Wang W, Zhang N, Jia S, et al. (2011) Case study: Numerica simulation of surfactant flooding in low permeability oil field. A paper presented at presented at SPE Enhanced Oil recovery. Conference held in Kuala Lumpur, Malaysia. 
Citation: Prince MJA (2017) Improving Recovery Through Surfactant Desorption on An Oil Wet Limestone Reservoir. J Pet Environ Biotechnol 7: 319. doi: 10.4172/2157-7463.1000319

9. Samanta A, Ojha K, Sarkar A, Mandal A (2011) Surfactant and surfactantpolymer flooding for enhanced oil recovery. Advances in Petroleum Exploration and Development 2: 13-18.

10. Wever DAZ, Ramalho G, Picchioni F, Broekhuis AA (2013) Acrylamide-b-NIsopropylacrylamide block copolymers: synthesis by atomic transfer radical polymerization in water and the effect of the hydrophilic-hydrophobic ratio on the solution properties. J. Appl. Polym. Sci. 131: 39785.

11. Hongya W, Xulong C, Jichao Z, Aimei Z (2009) Development and Application of Dilute Surfactant-Polymer Flooding System for Shengli Oilfield. J. Pet. Sci. Eng. 65: 45-50.

12. Julius $P$ (2015) Analysis on capillary pressure curves by wettability modification through surfactants. Indian Journal of science and technology.

13. Ahmadi MA, Shadizadeh SR (2012) Adsorption of novel nonionic surfactant and particles mixture in carbonates: Enhanced oil recovery implication. 26: 4655-4663.

14. Nasralla RA (2012) Double-layer expansion: Is it a primary mechanism of improved oil recovery by low-salinity waterflooding? Society of Petroleum Engineers.

15. Bo Gao MMS (2012) A New Family of Anionic Surfactants for EOR Applications Society of Petroleum Engineers, USA.

16. Salari Z, Ahmadi MA, Ahmadi R, Kharrat R, Shahri AA (2011) Experimental studies of cationic surfactant adsorption onto carbonate rocks. Australian Journal of Basic and Applied Sciences 5: 808-813.

17. Austad T (2010) Chemical mechanism of low salinity water flooding in sandstone reservoirs. Society of Petroleum Engineers. USA. 